\title{
As faces de Jano: as relações entre capital e interior no estado do Rio de Janeiro
}

\section{Linovaldo Miranda Lemos}

\section{Introdução}

Jano (ou Janus) era uma antiga divindade romana que representava os começos, o início de todas as coisas. Era considerado o porteiro dos céus, comumente representado como um ser bifronte, guardião das portas, protetor das chegadas e das partidas, do devir e do porvir. (HACHETTE, 1996; COMMELIN, 1960). O mês que abre o ano no nosso calendário lhe é dedicado e este, por sua vez, empresta o nome à terra encontrada nos trópicos pelos portugueses, conforme é comumente reputado.

O presente trabalho se dedica ao estudo das relações entre as duas faces do estado do Rio de Janeiro, representada pela capital, o antigo estado da Guanabara e o interior, o antigo estado do Rio de Janeiro. Para tal intento recorre-se, como caminho metodológico, à pesquisa bibliográfica, procurando-se analisar - e fazer dialogar - as interpretações sobre essa trajetória de constituição territorial. Mirou-se, nessa revisão bibliográfica, no papel atribuído a cada uma dessas partes a fim de fazer-se revelar as sucessivas aproximações e distanciamentos entre ambas. Nesse sentido, opta-se aqui por desenvolver quatro temáticas congruentes e inter-relacionadas, a saber, o papel de capitalidade da cidade do Rio de Janeiro (Rio) e as consequências para a relação com o Estado do Rio de Janeiro (ERJ); o processo de fusão e o papel do interior como solução ou como problema político-territorial; o discurso da crise, muitas vezes revestido do sentimento de uma época perdida e das dificuldades do tempo presente, tomado como tensionadores ou elementos de desequilíbrio nessa relação e, por fim, antes das considerações finais, as dinâmicas territoriais atuais e o papel do interior.

Considera-se que essas temáticas são centrais nas discussões sobre o ERJ e que não só ajudam a compreender o arranjo territorial atual do estado como também sua singularidade no conjunto dos entes federados. Como se demonstrará, tal via singular e sinuosa de constituição dessa unidade da federação, deixou como legado uma realidade geopolítica marcada por constantes movimentos de aproximação e distanciamento entre capital e interior que são reveladores de certa tensão existente entre elas. Fruto de um processo histórico marcado por dicotomias, diferenciações e, ao mesmo tempo, por complementaridades e interesses recíprocos, o Rio de Janeiro constitui-se hoje numa realidade geopolítica de um estado com duas "faces" ou unidades num processo de difícil amalgamento. Nesse contexto, metaforicamente, o desafio talvez seja, qual Juno do mito romano, o Rio de Janeiro tornar-se de fato, ao mesmo tempo, uno e bifronte.

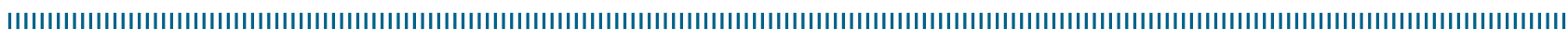
Como citar este artigo:

LEMOS, Linovaldo Miranda. "As faces de Jano: as relações entre capital e interior no estado do Rio de Janeiro”. In: RÜCKERT, A. A.; SILVA, A. C. P. da; SILVA, G. de V. (Orgs.). Geografia Política, Geopolítica e Gestão do Território: integração sul-americana e regiões periféricas. Porto Alegre: Editora Letra1, 2018, p. 319-328 DOI 10.21507/9788563800367-20 


\section{A capitalidade da cidade do Rio de Janeiro entre aproximações e distanciamentos em relação ao estado do Rio de Janeiro}

A capitalidade se refere ao papel desempenhado por uma cidade como centro de decisão - portanto de poder - de uma nação. Trata-se de um conceito tomado do trabalho de Giulio Argan ${ }^{1}$ (1964 apud MOTTA, 2001) e se refere à capacidade de uma cidade em constituir-se como uma identidade e símbolo de uma nação. Cidades-capitais são, assim:

Sedes da autoridade do Estado, dos órgãos do governo e da administração pública [...] lugar da política e da cultura, como núcleo da sociabilidade intelectual e da produção simbólica, representando, cada um à sua maneira, o papel de foco civilização, núcleo da modernidade, teatro do poder e lugar de memória. (MOTTA, 2001, p. 24).

O conceito de capitalidade é utilizado pela bibliografia sobre o ERJ para designar e qualificar o papel desempenhado pela cidade do Rio de Janeiro, ao longo da história ${ }^{2}$, como centro político-administrativo do país, sede do poder

||||||||||||||||||||||||||||||||||||||

1 Giulio Carlo Argan (1909-1992), crítico de arte, professor, historiador italiano. Desenvolveu também carreira política como prefeito de Roma e senador da República. A obra na qual desenvolveu a ideia de capitalidade e que influenciou o pensamento sobre o papel do Rio de Janeiro foi GIULIO, Argan. L'Europe des capitales. Gèneve, Albert Skira, 1964. Disponível em: <http:// www.giuliocarloargan.org/>.

2 Com vistas à melhor compreensão desse processo e da temática de que trata o presente artigo, destacam-se os seguintes marcos: 1565 : fundação da cidade do Rio de Janeiro; 1763: transferência da capital da colônia portuguesa de Salvador para a cidade do Rio; 1808: vinda da família real para o Brasil, Rio elevado à condição de Reino Unido de Portugal e Algarves; 1824: criação da província do Rio de Janeiro mantendo a cidade do Rio a condição de capital do Império; 1834: a cidade do Rio passa a ser "município neutro". Como resultado, a cidade se desvincula do estado de mesmo nome e este passa a ter autonomia administrativa; 1889: República, a cidade do Rio se torna Distrito Federal e a antiga província se torna Estado do Rio de Janeiro; 1960: transferência da capital para Brasília; 1960-1974/1975: cidade do Rio de Janeiro se torna um estado da Federação, a Guanabara, separado do Estado do Rio de Janeiro, esse com sua capital em Niterói; 1975: Fusão (MENEZES et. al., 2016; FERREIRA \& GRYNSZPAN, 2015; LESSA, 2005; BRASILEIRO, 1979). político e dos órgãos da administração pública, além de centro cultural e mesmo de relativo polo econômico. (MOTTA, 2001; 2015; LESSA, 2005). Como "caixa de ressonância" do país como comumente foi qualificada - a cidade do Rio de Janeiro assumiu o papel de catalisador da política e das grandes discussões nacionais, fazendo convergir interesses e demandas oriundos de todo o território nacional e desempenhando o papel de centro difusor de poder.

Diante desse papel de centralidade desempenhado pela cidade do Rio de Janeiro cabe indagarem-se duas questões correlacionadas daí advindas. Em primeiro lugar, há um pressuposto comumente aceito de que as elites fluminenses alinharam-se muito mais às preocupações com os rumos do país do que com a defesa dos interesses locais. Assim, para além das implicações políticas, econômicas, sociais e culturais advindas da condição de capitalidade, tal fato teria trazido consigo, como um de seus efeitos, a relegação das discussões da escala local ou regional-estadual a um segundo plano. No entanto, como pensar nas especificidades da política local, nos interesses e nas dinâmicas da própria cidade e do Estado do Rio de Janeiro?

Uma visão mais nuançada se faz necessária a respeito desse primeiro aspecto ou questão. Ferreira e Dantas (2015) nos alertam que há que se questionar a visão comumente estabelecida pela historiografia de que a história da cidade seja "um capítulo da história nacional relegando a um segundo plano a lógica interna da política carioca, ou até mesmo negando a sua existência". (FERREIRA \& DANTAS, 2015, p. 68). Como demonstraram esses autores, há que ter em mente as estratégias de atuação de grupos políticos cariocas como formas de enfrentamento das constantes interferências do governo federal na cidade do Rio no contexto da política nacional dos anos 1940 e 1950, de forma a compreenderem-se as intrincadas relações entre o poder local e o poder central. Em segundo lugar, há que se acrescentar a essa equação o fato de que a própria centralidade, ao fim e ao cabo, significou uma proximidade da cidade com as "esferas de poder de ordem distinta 
à de suas limitações espaciais" o que acarretou uma "radical clivagem interna entre o espaço do poder e o do cotidiano da população" criando "formas de convivência e adaptação" (SARMENTO, 2015, p. 40). Portanto, talvez a questão posta entre a aparente dicotomia entre o "Rio Nacional, Rio Local", conforme sugestivo título do livro de OSÓRIO (2005), seja justamente o caráter e o escopo da atuação das elites fluminenses no necessário esforço de pensar a formulação de políticas públicas voltadas à solução de problemas estruturais da economia fluminense.

Uma segunda ordem de questionamentos se refere ao problema que o presente artigo trata diretamente, a saber, as relações entre a capital e o seu entorno mais imediato, o ERJ ou, nos termos colocados por Motta (2007), a necessária compreensão da tensão entre o "Rio de Janeiro versus o Rio de Janeiro". A leitura atenta da bibliografia sobre o tema revela que esta tem sublinhado muito mais os aspectos concernentes ao distanciamento e às diferenças entre as duas partes do que aqueles elementos de aproximação. De forma geral, tal literatura argumenta que há uma carência de coesão interna bem como uma separação e autonomia entre a capital e o interior, ao ponto de considerar-se que a cidade e estado “criaram ao longo da história duas vidas, se não autônomas, pelo menos paralelas e relativamente independentes" (GALVÃO, 2009, p. 89), o que trouxe consigo, do ponto de vista da "identidade fluminense" (se é que se pode falar assim), uma "ausência do imaginário de um pertencer coletivo das populações, em função da inexistência de coesão e de laços de solidariedade territorial". (DAVIDOVICH, 2001; RIBEIRO, 2017). Subjacente ainda a esses argumentos está a ideia que associava:

a existência de uma lógica atrasada e clientelista vigente no antigo Estado do Rio de Janeiro teria trazido prejuízos para a nova institucionalidade surgida a partir de 1974, esquecendo-se de levar em conta que a política no novo estado é hegemonizada a partir da base clientelista organizada por Chagas Freitas no território carioca. (OSÓRIO, 2005, p. 262).

Grosso modo, são baseados nesses pressupostos da fragilidade e artificialidade dos laços que unem cariocas e fluminenses bem como nas diferenças das suas respectivas culturas políticas que se baseiam grande parte das críticas à fusão, o que veremos a seguir.

\section{O processo de fusão e o papel do interior ou como um problema ou como uma solução}

As relações entre capital e interior no Rio de Janeiro têm seu momento decisivo com a fusão. Isso não só pelo motivo óbvio da junção de duas unidades político-administrativa numa verdadeira "engenharia territorial" ${ }^{3}$ levada a cabo pelo regime militar, como também pelos discursos recorrentes na literatura, em fontes jornalísticas ou mesmo nos debates contemporâneos de movimentos a favor da "desfusão", de que a crise econômica persistente decorre não só da transferência da capital do país para Brasília, na década de 1960, como também devido ao processo de fusão dos antigos Estados da Guanabara e do Rio de Janeiro em 1975. Destituída de sua condição de capitalidade, e mesmo do status de um estado autônomo no contexto da federação, a Guanabara, passa a compor um novo estado, com o Rio de Janeiro, a "velha Província”. Para seus críticos, a fusão representaria a junção da rica cidade do Rio de Janeiro e um interior falido. (LIMONAD, 2004; LESSA, 2005; OSÓRIO, 2005; URANI, 2008).

A discussão sobre a transferência da capital federal e, consequentemente, o destino da cidade e do ERJ sempre estiveram em pauta. Cabe ressaltar que as Constituições de 1891, de 1934 e de 1946 já preconizavam a transferência da capital para o interior do Brasil. Já na década de 1940 podemos encontrar diversos estudos publicados na Revista Brasileira de Geografia do Instituto Brasileiro de Geografia e Estatística (IBGE), com as considerações geográficas, geopolíticas, técnicas, administrativas da localização na nova capital,

IIIIIIIIIIIIIIIIIIIIIIIIIIIIIIIIII

3 Entendido como os "mecanismos geopolíticos utilizados pelos poderes instituídos para a definição de projetos específicos de gestão do território de dada unidade político-institucional". (SILVA, 2011). 
indicando-se, para isso, áreas no Planalto Central (CASTRO, 1946; 1948). Em artigo de 1965, na mesma revista, propunha-se abertamente a fusão tomando por pressuposto "o fato histórico de ser o atual estado da Guanabara parte da antiga província do Rio de Janeiro, da qual foi tomada de empréstimo a fim de formar o "Município Neutro" [...]" (GRANDE, 1965, p. 163 grifos nossos) ${ }^{4}$. Os estudos de Marli Motta, por seu turno, demonstraram no contexto da transferência da capital houve um intenso debate na imprensa e na política sobre os rumos que da cidade do Rio deveria tomar a partir da necessária "definição de uma nova identidade para a cidade-capital do Brasil”. (MOTTA, 2004, p. 12).

Como se vê, diferentemente do que parece ao olhar retrospectivo mais superficial, não se tratava de uma "surpresa" ou de algo que, de alguma forma, não estivesse em pauta no horizonte político, tanto em perspectiva histórica quanto no momento da transferência. Ferreira e Grynszpan (2015) argumentam que, nos debates a respeito dos destinos da antiga Capital Federal, ainda nos anos 1950, as discussões se centravam no problema político relativo à garantia da "autonomia do Rio em face das possíveis ameaças de intervenção federal" (p. 145) não obstante também estivesse em discussão a necessidade de criação de um estado forte, política e economicamente, a partir da junção das duas unidades político-administrativas.

Nos anos 1970, no entanto, o debate passa a evocar argumentos mais técnicos diríamos, na verdade, geopolíticos - relativos ao desenvolvimento nacional mediante a criação de um polo alternativo de desenvolvimento com a integração das potencialidades das duas economias, libertando o país da estreita dependência em relação a São Paulo. (FERREIRA, GRYNSZPAN, 2015). Nesse contexto, há que se chamar a atenção para as inter-relações entre a Guanabara e a área contígua à metrópole, a

||I||||||||||||||||||||||||||||||||||||

4 Nas décadas de 1960 e 1970 e 1980 diante do fato consumado da transferência, podemos notar que os estudos, nessa mesma revista, se voltam para as questões relativas à estrutura urbana e administrativa do Estado do Rio de Janeiro (DUARTE, 1981; SANT'ANNA, 1976; GEIGER, 1960; TEIXEIRA, 1975).
Baixada Fluminense, Niterói e São Gonçalo e os argumentos daí advindos favoráveis à fusão em consonância com a propalada necessidade de integração da metrópole à sua hinterlândia 5 . A fusão, em suma, representaria uma saída para os problemas do "esvaziamento econômico" da Guanabara fruto, dentre outros fatores, da perda da sua condição de capitalidade, via junção com o ERJ.

Não é possível, no entanto, desconsiderar ou minimizar o caráter autoritário da media tendo em vista a não consulta, nem à população da Guanabara e nem à do Estado do Rio de Janeiro, com relação aos destinos das duas unidades. Para Brasileiro (1979), a fusão vem coroar um modelo de funcionamento do sistema baseado na centralização do poder e do planejamento do desenvolvimento econômico do país que relegaram ao segundo plano a participação da sociedade civil na promoção de um amplo debate sobre o processo.

Por outro lado, a fusão representaria, para os seus defensores, uma "correção" do percurso inaugurado com a separação da antiga província do Rio de Janeiro e o Município Neutro, a cidade do Rio de Janeiro, em 1834. A fusão, nesse sentido, representaria a retomada de uma configuração territorial "original", o reencontro de duas partes anteriormente separadas. De forma muito assertiva, Ferreira e Grynszpan (2015), assim sintetizam o debate:

Para os que procuravam justificar a fusão, portanto, ela era inexorável, era uma exigência histórica que vinha se operando de facto. O que cabia era realizá-la de jure, eliminando as barreiras artificiais, permitindo que a história retomasse seu curso natural original. Para os críticos da ideia de fusão, no entanto, não se poderia mais falar, também historicamente, de um único curso, mas de dois, distintos. O artificial, nessa perspectiva, seria tentar fazê-los confluir, numa iniciativa que produziria, com certeza, efeitos perversos. (FERREIRA, GRYNSZPAN, 2015, p. 144). 
Robson Dias defende a tese de que sempre teria havido uma noção de unidade entre a cidade do Rio e o seu entorno, o ERJ. Questiona-se, nesse sentido, a razão de uma cidade do porte do Rio não ter sido capaz de dinamizar o seu entorno, seja a sua periferia metropolitana, seja o seu interior. Segundo este autor, as causas devem ser buscadas justamente na capacidade de "drenagem" de grande parte da renda gerada no território fluminense para a capital. Como centro político, econômico e financeiro a capacidade de polarização da cidade do Rio teve como efeito um atrofiamento do desenvolvimento urbano do interior. (DIAS, 2015). Analisando outro contexto histórico, aquele da "inflexão econômica positiva" de meados dos anos 1990 quando o ERJ sai de um período de crise que se arrastou desde pelo menos meados dos anos 1980, Natal (2005) reputa justamente ao interior a responsabilidade por esse fôlego de superação da crise.

Como se vê, as relações de aproximação e de distanciamento entre a cidade do Rio e o interior se manifestam nas interpretações do papel relativo de cada uma dessas "partes" na sua trajetória histórica de desenvolvimento econômicoterritorial.

\section{O discurso da crise ontem e hoje: o Rio de Janeiro do desânimo e da euforia}

A temática da "crise" tem sido um terreno constantemente visitado pela bibliografia especializada nas questões concernentes ao ERJ. Há que se levar em consideração, que essa crise se manifesta tanto na escala do ERJ quanto na da cidade do Rio e que, muito embora seja um fenômeno obviamente interligado nos dois casos, possui suas especificidades, tanto nas suas explicações quanto nas formas de percepção e de elementos evocados para descrevê-la.

Como vimos, na escala da cidade do Rio a literatura chama a atenção para os efeitos que a perda da capitalidade representou para a cidade. Corroborando ou refutando, de forma aberta ou velada, tal fato faz emergir questões como a perda da renda da cidade representada pela transferência da capital e de sua burocracia para Brasília e os efeitos que isso representou para a cidade do Rio em função do próprio peso do setor público. (MOTTA, 2001a). Por outro lado, ainda, o esgotamento do modelo de política econômica do regime militar ("Brasil Grande"), nos anos 1980, faz cessar os investimentos federais no país e a consequente interrupção de grandes obras financiadas por esses recursos federais na cidade do Rio, agravando sua situação. (MOTTA, 2001b; NATAL, 2005). O trabalho de Motta (2004) demonstrou que os meios de comunicação e a imprensa, no geral, reputam grande parte dessa crise à própria fusão em decorrência de uma trajetória de perdas impostos a cidade do Rio pelos "sucessivos arranjos institucionais": transferência da capital, extinção da Guanabara e o rebaixamento da cidade do Rio à condição de município. No entanto, Jorge Natal (2005) se refere a essas alegadas "perdas" como sendo uma "ideologia de expiação e externalização de culpas" (p. 35) e propõe analisar o quadro dentro de um contexto ou perspectiva mais ampla relativa ao desenvolvimento da economia capitalista nacional - estabelecida em São Paulo - e as fragilidades da própria economia fluminense.

No que se refere ao escopo proposto para o presente texto, podemos dizer que a literatura tem chamado a atenção para as oscilações entre períodos de maior ou menor crise e intervalos de crescimento e expansão das atividades econômicas. Talvez a marca do ERJ tenha sido justamente um movimento pendular, oscilante entre períodos de crescimento econômico e de importância relativa no cenário nacional e períodos de acentuada crise econômica e social. Crise e desânimo se alternam com momentos de euforia quase ufanista que se refletem nas interpretações da bibliografia sobre o tema, não por uma interpretação incorreta ou por um erro de avaliação dessa mesma bibliografia, mas sim pelo caráter de certa forma errático e instável desse processo ${ }^{6}$.

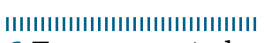

6 Tome-se, a título de exemplo disso que estamos falando aqui, a caracterização de um curto período de tempo: "Um período de crescimento instável até 2004 e uma retomado do crescimento a partir deste ano, mas com uma inflexão em 2009 provocada pela 
No entanto, tão importante quanto a temática da crise está a da sua superação, seja enquanto tendência real de cada momento histórico, seja como desejo ou projeção de um futuro esperado. A bem da verdade, a ênfase dos estudos continua sendo a cidade do Rio e, ainda muito subsidiariamente, o Estado do Rio de Janeiro. De qualquer forma, podemos notar um movimento no qual o pêndulo da interpretação recai ou sobre os aspectos da crise intermitente ou, por vezes, sobre as potencialidades de superação dessa mesma crise ${ }^{7}$. Por vezes essa perspectiva de superação se traduziu em esforços que compreendiam ter chegado a "hora da virada" (URANI, GIAMBIAGI, 2011) para o ERJ, ou que tivesse chegado "a hora e a vez do Rio”. (VELLOSO, 2007). Os sinais alvissareiros se espalhavam, nessas visões, na projeção de investimentos em polos de desenvolvimento no estado (químico-farmacêutico, naval, metalmecânico, turismo, etc), no setor de petróleo, nos efeitos dos grandes eventos, nos investimentos em infraestrutura, logística e setor portuário. No entanto, o tempo mostrou os efeitos reduzidos e a perda dessa oportunidade vislumbrada. O recente acirramento da queda do volume de emprego formal e da arrecadação, que se traduzem numa profunda crise fiscal no ERJ (MERCÊS; FREIRE, 2017; SANTOS; NAZARETH, 2017), colocam em xeque a capacidade do estado de reverter o seu quadro atual de crise. Some-se a isso o mau uso dos recursos públicos, a corrupção, as oscilações (com tendência à queda) do preço do barril do petróleo e de toda gama de instabilidades políticas decorrentes desses fatos, para nos apercebermos

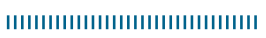

crise internacional de 2008". (HASENCLEVER, PARANHOS \& TORRES, 2012, p. 684).

7 Não se está aqui questionando o mérito, a qualidade ou a importância desses estudos, mas sim ressaltar que muito do que se escreve sobre o Rio de Janeiro, especialmente sobre a sua capital, é envolto por um sentimento de "orgulho de ser coproprietário da cidade" e "amante do Rio", como se declarou Carlos Lessa (2005, p. 17). Dessa relação de amor propõe-se uma reflexão em "busca de autoestima" a propósito do estudo do "Rio de todos os Brasis". Para fechar esse ponto, vale a pena recorrer-se, como argumento, às palavras de Merval Pereira ao prefaciar o livro "Trilhas para o Rio: do reconhecimento da queda à reinvenção do futuro". Para o jornalista, o livro de André Urani (2008) é "ao mesmo tempo um estudo científico e uma ode de amor ao Rio de Janeiro [...]”. da enorme distância entre essas projeções de excessivo otimismo e a difícil realidade política, econômica e social por que passa hoje o ERJ.

\section{Dinâmicas territoriais atuais de um estado e o crescimento relativo das áreas fora da capital}

Como foi discutido até o momento, as temáticas da perda da capitalidade, da fusão e das crises são importantes elementos na discussão sobre o ERJ. O tópico que ora abordaremos se relaciona aos anteriores como um contraponto ao discurso da crise, alertando para a importância da observação das dinâmicas territoriais atuais no ERJ em direção a uma compreensão de processos mais amplos concernentes ao crescimento relativo de áreas fora da capital e da Região Metropolitana. Trata-se de estudos que, mesmo não negando a prevalência dessas áreas no contexto estadual, propõem um olhar para outras dinâmicas no chamado "interior".

Jacob Binsztok (1999) apontou para a ideia de que, no contexto da crise, estar-se-ia construindo "uma nova ordem territorial no estado do Rio de Janeiro" com a "reestruturação" do espaço fluminense a partir de investimentos em certos setores. No seu texto de 2004, Ester Limonad propõe analisar o ERJ a partir de suas dinâmicas internas que se traduziriam em novas relações entre a capital e o interior. Chama a atenção, nesse sentido, para uma redistribuição das atividades produtivas e da população no território às quais, destarte não ter provocado uma mudança no peso acentuado da cidade e da Região metropolitana do Rio de Janeiro, gerou uma complexificação da realidade estadual em decorrência de investimentos fora da capital, do crescimento de setores produtivos e da ampliação de espaços urbanos em outras regiões como nas Baixadas Litorâneas.

$\mathrm{Na}$ identificação dessas áreas ou zonas de maior crescimento no interior, a bibliografia tem apontado uma dinâmica calcada em eixos de circulação viária representada pelas rodovias e sua capacidade de atração e de fixação de populações e de atividades econômicas (LIMONAD, 2004; 
MEDEIROS JÚNIOR, 2013) ou daquilo que João Rua (2007) conceituou como "urbanidades no rural" se referindo a "territórios híbridos nos quais o urbano e o rural interagem" (p. 273) a partir de processos de absorção materiais e imateriais, em áreas rurais, de melhorias nos meios de comunicação, infraestrutura, novas formas de lazer, serviços e atividades econômicas como o turismo e a segunda residência, dentre outros, que têm provocado mudanças importantes no campo no ERJ. (MARAFON, 2017). Ao longo das principais rodovias, esses eixos formariam "novas territorialidades em áreas rurais" em certos espaços fluminenses ${ }^{8}$.

Imbuídos do reconhecimento da importância do estudo do ERJ para além do núcleo metropolitano uma série de estudos tem se dedicado ao chamado "interior". Dentro dos limites do presente artigo chamamos a atenção para o fato de que tais estudos se referem a abordagens que privilegiam diferentes setores e atividades (agricultura familiar, patrimônio histórico, petróleo, produção de hortifrutigranjeiros, lácteos, setor metal-mecânico, portuário, etc) em abordagens que têm como objeto principal de análise os municípios e suas interações com suas respectivas regiões, ou ainda, as regiões político-administrativas do estado, destacandose eventualmente determinado (s) município (s). São trabalhos que se propõem a compreender as lógicas daqueles setores nos espaços municipais e regionais (portanto nas escalas local, micro e meso regional) no contexto estadual de forma a revelar as dinâmicas sócio-territoriais não só na capital como também na crescente importância do interior. (FAURÉ \& HASENCLEVER, 2003; 2005; FAURÉ, HASENCLEVER \& NETO, p. 2008; MARAFON \& RIBEIRO, 2003; 2008; 2010; 2012).

Com alguma dose de exagero, Fonseca (2006) se refere a uma "ascensão do interior" no ERJ, visão essa que deve ser tomada com as devidas

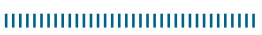

8 João Rua espacializa esse processo que chama de "interiorização" e "desconcentração" identificando as seguintes áreas: o eixo da Região Serrana, eixos Litorâneos (Baixada Litorânea e Rio-Santos), eixos das rodovias Rio-São Paulo e Rio-Juiz de Fora e do Vale do Paraíba. ressalvas e o reconhecimento de que apesar do relativo decréscimo da participação econômica da Região Metropolitana, vis-à-vis as demais regiões de governo no ERJ, esta continua concentrando mais de $60 \%$ do PIB e $72 \%$ da população estadual, segundo dados do IBGE. Em outras palavras, mesmo cientes das dinâmicas atuais do "interior", o ERJ continua a ter um forte componente metropolitano (ALENTEJANO, 2005; RIBEIRO, 2013), o que se traduz no peso que a cidade e a Região Metropolitana do Rio de Janeiro possuem no contexto estadual com sua forte concentração de população, de atividades econômicas, de arrecadação e de investimentos.

Há que se ter em conta, que a reestruturação produtiva a que se referem os autores não se dá de forma equilibrada no território, mas antes de forma concentrada em certas regiões, em certos municípios centrais dessas regiões e em certas atividades econômicas. Chama a atenção, nesse sentido, o crescimento da população e do emprego nas regiões Norte Fluminense, Baixadas Litorâneas e Médio Vale do Paraíba desde os anos 2000, alavancados, respectivamente, pelo setor petrolífero, os royalties e as atividades turísticas e o complexo metal-mecânico e automobilístico. (MEDEIROS JÚNIOR, 2013; PEREIRA, 2013). Já as regiões Noroeste e Centro-Sul Fluminense, apesar da melhoria nos indicadores sociais, não conseguiram aumentar sua participação no PIB, emprego e população no contexto estadual. (LEMOS \& PIRACIABA, 2016; NETO \& ROCHA, 2013).

O olhar atento sobre o volume de investimentos - realizados e previstos - no ERJ coloca em dúvida os limites e o alcance desse processo de desconcentração em direção ao interior fluminense. É o que demonstra o estudo de Neto e Rocha (2013) para o volume de empregos e investimentos entre os anos de 2002 e 2013. Segundo os autores,

embora os investimentos estejam espalhados pelo Estado do Rio de Janeiro, observa-se que eles têm se concentrado, crescente e prioritariamente, na Região Metropolitana do Rio de Janeiro e em suas regiões circunvizinhas. (p. 5).

No que se refere especificamente ao Norte 
Fluminense, área para os quais os dados indicam crescimento da renda e da participação da indústria no montante do PIB, há que se terem as devidas precauções em relação aos reais impactos desses dados "brutos" em relação ao "espaço banal" (SANTOS, 2001) das populações ${ }^{9}$ : em outras palavras, esses dados não se consubstanciam em melhorias reais para o dia a dia do cidadão comum com a maior oferta de emprego, por exemplo. Por um lado, o peso da renda petrolífera nos orçamentos municipais trouxe consigo uma série de efeitos deletérios que poderiam ser sintetizados na tese da "maldição dos recursos naturais"10: preguiça fiscal, mau uso dos recursos públicos, instabilidade política, corrupção, dependência financeira de recursos finitos e sujeitos às oscilações nos preços dessas commodities no mercado internacional. Por outro lado ainda, há que se ter em conta que os dados do crescimento do PIB industrial devem ser creditados ao petróleo, o que, nem sempre, se traduz, efetivamente, em aumento da renda real, do emprego e da qualidade de vida das populações desses municípios. (CRUZ, 2005; CRUZ \& NETO, 2014; GIVISIEZ \& OLIVEIRA, 2007; MACIEL, 2014; PESSANHA, 2013).

\section{Palavras finais}

Certa feita o sociólogo campista José Luis Viana da Cruz qualificou o debate sobre o ERJ como sendo "carioca-centrado" (CRUZ, 2013), numa clara referência ao fato de que as vozes que narraram e narram a história e as interpretações

||IIIIIIIIIIIIIIIIIIIIIIIIIIIIIIIII

9 A noção de "espaço banal" foi utilizada por Milton Santos para referir-se ao "cotidiano compartilhado", que cria “a interdependência obrigatória e da solidariedade, geradas pelas situações de cara a cara". (SANTOS, 2001, p. 258).

10 Para MACIEL (2015, p. 255): “[...] os recursos naturais não são uma maldição para o progresso socioeconômico [...] tampouco os recursos naturais são uma bênção ou salvação, frente aos dolorosos dilemas que frequentemente tornam tortuosas suas trajetórias de desenvolvimento. [...] não se trata de concluir pela bênção ou a maldição dos recursos naturais, até porque a história das experiências de desenvolvimento guardam exemplos que são compatíveis com ambas as hipóteses, evidenciando que não é a riqueza natural espraiada sobre o território de uma nação o fator chave para sua fortuna ou desgraça. Assim, o progresso não é uma função do estoque dos seus recursos naturais, mas sim de sua articulação com as potencialidades de um país (e de seus cidadãos)." sobre essa unidade da federação partiram da capital do Estado. No nosso entendimento, para além de refletir o peso da cidade do Rio no contexto do estado, qualificar o debate como sendo "carioca-centrado" refletiria um ponto de vista e, ao mesmo tempo, um elemento para a compreensão de certa tensão a que o presente texto se dedicou. Como procuramos demonstrar, o debate sobre as dinâmicas territoriais no ERJ podem ser compreendido a partir dos vieses da condição da capitalidade, do discurso da crise e de sua superação e das "novas" dinâmicas processadas em outros espaços, que não a Região Metropolitana do Rio de Janeiro e da própria cidade do Rio.

A análise da bibliografia sobre o ERJ e sobre a cidade do Rio revela enorme riqueza de interpretações e possibilidades de estudos. O presente artigo procurou trazer elementos para esse debate, a partir daqueles vieses já referidos. Obviamente, trata-se de uma análise não exaustiva, aberta, mas que intenta contribuir com as interpretações sobre essas dinâmicas territoriais do ERJ tendo em mente um esforço de fornecer balizas para se compreender a bibliografia sobre o tema.

Marcada por dicotomias, o debate sobre as relações entre capital e interior no ERJ ensejou evocar o mito romano de Jano, o deus de duas faces. Não parece haver nesse mito, nenhuma oposição entre a concepção dupla-uma bem como nenhuma atribuição de caráter valorativo (positivo, negativo, conservador, avançado) em relação às duas faces do deus. Ele é, ao mesmo tempo, um ser bifronte e uno. Resta perguntarmonos se, diante das vicissitudes e possibilidades do ERJ, qual será seu ethos enquanto unidade da federação e local de existência de seus moradores.

\section{Referências}

ALENTEJANO, Paulo Roberto R. A evolução do espaço agrário fluminense. GEOgraphia, Ano 7, n. 13, 2005.

BINSZTOK, Jacob. Crise e construção de uma nova ordem territorial no estado do Rio de Janeiro. GEOgraphia, Ano 1, n. 2, 1999.

BRASILEIRO, Ana Maria. A fusão: análise de uma política pública. IPEA/IPLAN, Brasília, 1979. 
CASTRO, Christovam Leite de. A transferência da capital do país para o Planalto Central. Rio de Janeiro, Revista Brasileira de Geografia, Ano VII, n. 4, out/set. 1946, p. 567-572.

CASTRO, Christovam Leite de. A mudança da capital do país. Rio de Janeiro, Revista Brasileira de Geografia, Ano X, n. ${ }^{\circ}$ 3, jul/set. 1948, p.449-451.

COMMELIN, Pierre. Mythologie grecque et romaine. Paris, Éditions Garnier Frères, 1960.

CRUZ, J. L. V., AZEVEDO NETO, J. A. Assimetrias e desigualdades nos impactos do Complexo Petrolífero do Norte Fluminense: os casos de Campos dos Goytacazes e Macaé. Petróleo, Royalties e Região, v. X, p. 10-15, 2014.

CRUZ, J. L. V., AZEVEDO NETO, J. A. "Os desafios da construção do desenvolvimento no Rio de Janeiro". Cadernos do Desenvolvimento Fluminense, Rio de Janeiro, n. 2, jul. 2013.

DAVIDOVICH, Fany. Metrópole e território: metropolização do espaço no Rio de Janeiro. Cadernos Metrópole, n. 6, pp. 67-77, $2^{\circ}$ sem. 2001.

DIAS, Robson. Vida e morte da questão regional no Estado do Rio de Janeiro pós-fusão: o caso da FUNDREM. Tese, Doutorado em Planejamento Urbano e Regional, Universidade Federal do Rio de Janeiro, 2015.

DUARTE, Haldine da Silva Barros. Estrutura urbana do Estado do Rio de Janeiro: uma análise no tempo. Revista Brasileira de Geografia, v. 43, n.4, out/dez 1981, p. 447560.

FAURÉ, Yves A; HASENCLEVER, Lia. (Org.) O desenvolvimento local no estado do Rio de Janeiro: quarto estudos exploratórios no interior fluminense. Rio de Janeiro: E-papers, 2003.

FAURÉ, Yves A; HASENCLEVER, Lia. (Org.) O desenvolvimento local no estado do Rio de Janeiro: estudos avançados nas realidades municipais. Rio de Janeiro: E-papers, 2005.

FAURÉ, Yves A; HASENCLEVER, Lia. NETO, Romeu e S. (Org.) Novos rumos para a economia fluminense: oportunidades e desafios de crescimento do interior. Rio de Janeiro: E-papers, 2008.

FERREIRA, Marieta de Morais. DANTAS, Camila Guimarães. Os apaziguados anseios da terra carioca: lutas autonomistas no processo de redemocratização pós-1945. In: FERREIRA, Marieta de Moraes. Rio de Janeiro: uma cidade na história. Rio de Janeiro, FGV Editora, 2015, p. 65-88.

FERREIRA, Marieta de Morais. DANTAS, Camila Guimarães. GRYNSZPAN, Mario. A volta do filho pródigo ao ar paterno? A fusão do Rio de Janeiro. In: FERREIRA, Marieta de Moraes. Rio de Janeiro: uma cidade na história. Rio de Janeiro, FGV Editora, 2015, p. 131-153.

FREIRE, Américo. SARMENTO, Carlos Eduardo. MOTTA, Marly Silva. (Org.). Um estado em questão: 0s 25 anos do Rio de Janeiro. Rio de Janeiro, Editora FGV, 2001.

GALVÃO, Maria do Carmo Corrêa. Rio de Janeiro: contradições e ajustes de um espaço desigual. In:
Percursos geográficos. Rio de Janeiro: Lamparina, PPGG/ UFRJ, 2009.

GEIGER, Pedro Pinchas. Ensaio para a estrutura urbana do Rio de Janeiro. Revista Brasileira de Geografia, Ano 23, jan/mar. 1960, p.3- 44.

GEIGER, Pedro Pinchas; DAVIDOVICH, Fany Rachel. Reflexões sobre a evolução da estrutura espacial do Brasil sob o efeito da industrialização. Rio de Janeiro, Revista Brasileira de Geografia, Ano 36, n. 3, jul/set, 1974, p. 3-29.

GIVISIEZ, Gustavo Henrique N. OLIVEIRA, Elzina Lúcia de. A pobreza e a riqueza nas cidades do petróleo. In: PIQUET, Rosélia. SERRA, Rodrigo (org.). Petróleo e região no Brasil: o desafio da abundância. Rio de Janeiro, Garamond, 2007.

GRANDE, J. C. Pedro. Proposição de uma nova divisão política do Brasil. Revista Brasileira de Geografia, Ano 23, n. ${ }^{\circ} 2$, abr/jun. 1961, p.89-103.

GUERRA, Antonio Teixeira; GUERRA, Ignez Amelia L.T. Subsídios para uma nova divisão política do Brasil. Rio de Janeiro, Revista Brasileira de Geografia, n. 2, abr/julh. 1960, p.169-208.

HACHETTE. Dicionário da mitologia grega e romana. Lisboa, Edições Asa, 1996.

HASENCLEVER, Lia. PARANHOS, Julia. TORRES, Ricardo. Desempenho Econômico do Rio de Janeiro: Trajetórias Passadas e Perspectivas Futuras. DADOS-Revista de Ciências Sociais. Rio de Janeiro, v.55, n.3, 2012, pp.681711.

LESSA, Carlos. Rio de todos os Brasis: uma reflexão em busca de autoestima. Rio de Janeiro: Record, 2005.

LIMONAD, Ester. Rio de Janeiro, uma nova relação capitalinterior? In: LIMONAD, Ester. HAESBAERT, Rogério. MOREIRA, Rui (Org.). Brasil século XXI por uma nova regionalização? Agentes, processos e escalas. Niterói: Max Limonad, 2004, p. 7892.

MACIEL, F.. Trabalho e desenvolvimento no Norte Fluminense: para onde vamos? Petróleo, Royalties e Região, v. XI, p. 8-10, 2014.

MACIEL, Gregório da Cruz Araújo. Recursos naturais e desenvolvimento econômico: bênção, maldição ou oportunidade? Tese, Doutorado de Economia, Universidade Federal do Rio de Janeiro, Instituto de Economia, 2015.

MARAFON, Gláucio José; RIBEIRO, Miguel Angelo (Org.). Revisitando o Território Fluminense. Rio de Janeiro: Negef, 2003. v.1000. 251p.

MARAFON, Gláucio José; RIBEIRO, Miguel Angelo (Org.). Revisitando o Território Fluminense II. 1. ed. Rio de Janeiro: Gramma/FAPERJ, 2008. v.1000. 332p.

MARAFON, Gláucio José; RIBEIRO, Miguel Angelo (Org.). Revisitando o território fluminense III. 1. ed. Rio de Janeiro: Gramma/FAPERJ, 2010. v.1000. 354p.

MARAFON, Gláucio José; RIBEIRO, Miguel Angelo (Org.). Geografia do Estado do Rio de Janeiro: da compreensão do passado aos desafios do presente. Rio de Janeiro: Gramma, 2011. 
MARAFON, Gláucio José; RIBEIRO, Miguel Angelo (Org.). Revisitando o Território Fluminense IV. 1. ed. Rio de Janeiro: Gramma, 2012. v. 1000. 312p.

MARAFON, Gláucio José; RIBEIRO, Miguel Angelo (Org.). Quais mudanças em curso no campo fluminense? Geo UERJ. Rio de Janeiro, N.31, p. 356-370, 2017.

MERCÊS, Guilherme. RIBEIRO, Nayara. Crise fiscal dos Estados e o caso do Rio de Janeiro. Geo Uerj. Rio de Janeiro, N. ${ }^{\circ}$ 31, p.64-80, 2017.

NETO, Romeu e Silva. ROCHA, Maria das Dores. Avaliação dos impactos dos grandes projetos de investimentos na dinâmica do emprego formal no estado do Rio de Janeiro. Espaço e Economia. Ano III, n. 5, 2014, p.1-28. Disponível em: 〈https://espacoeconomia.revues.org/1345〉. Acesso em: 11 de abr. 2017.

MEDEIROS JUNIOR, Hélcio de. Desconcentração econômica e atratividade regional no estado do Rio de Janeiro entre 2000 e 2010. Cadernos do Desenvolvimento Fluminense. Rio de Janeiro, n.1, fev.2013. Disponível em: <http://www.epublicacoes.uerj.br/index.php/cdf/ article/view/9059/6937>. Acesso em: 13 de setembro de 2015.

MENEZES, Paulo Márcio Leal de. et al. A evolução políticoadministrativa do estado do Rio de Janeiro. Acervo, Rio de janeiro, v. 29, n. 1, p. 236-253, jan./jun. 2016.

MOTTA, Marly Silva da. Guanabara, o Estado-Capital. In: FERREIRA, Marieta de Moraes. Rio de Janeiro: uma cidade na história. Rio de Janeiro, FGV Editora, 2015, p. 89-129.

MOTTA, Marly Silva da. Rio de Janeiro versus Rio de Janeiro: o lugar da capital no cenário político fluminense. In: GOMES, Ângela Maria de Castro (Org.). Direitos e cidadania: memória, política e cultura. Rio de Janeiro: Fundação Getúlio Vargas, 2007, p. 175-196.

MOTTA, Marly Silva da. Rio de Janeiro: de cidade-capital a Estado da Guanabara. Rio de Janeiro, Editora da FGV, 2001.

MOTTA, Marly Silva da. FREIRE, Américo. SARMENTO, Carlos Eduardo. A política carioca em quatro tempos. Rio de Janeiro, Editora da FGV, 2004.

NATAL, Jorge. O estado do Rio de Janeiro pós 95: rede urbana, dinâmica econômica e questão social. Rio de Janeiro, Faperj, 2005.

OSÓRIO, Mauro. Rio Nacional, Rio Local: mitos e visões da crise carioca e fluminense. Rio de Janeiro, Senac, 2005.

OSÓRIO, Mauro. MELO, Luiz Martins de. VERSIANI, Maria Helena. WERNECK, Maria Lúcia. (Org.). Uma agenda para o Rio de Janeiro: estratégias e políticas públicas para o desenvolvimento socioeconômico. Rio de Janeiro, Editora da FGV, 2015.

PEREIRA, Regina Celi. Estado, território e reestruturação produtiva na metrópole fluminense. Espaço e Economia, Ano 2, n. 3, 2013, p. 1-12. Disponível em: <https:// espacoeconomia.revues.org/390>. Acesso em: 11 abr. 2017.

RIBEIRO, Luís César de Queiroz. As necessidades do planejamento urbano para o Estado do Rio de Janeiro. Revista de Economia Fluminense, Ano VII, n. 14, out. 2013.

RIBEIRO, Miguel A. Estado do Rio de Janeiro: das capitanias hereditárias a uma nova divisão regional. Geo UERJ, Rio de Janeiro, n. 31, p. 249-279, 2017.

RUA, João. "As crises vividas pelo estado do Rio de Janeiro e a emergência de novas territorialidades em áreas rurais". In MARAFON, Glaucio et al. (orgs.). Abordagens teórico-metodológicas em geografia agrária. Rio de Janeiro: EdUERJ, 2007, pp. 271-98.

PESSANHA, Cristiane Borba. Campos e Macaé na era do petróleo: evolução de indicadores na qualidade de vida. Dissertação de Mestrado. Universidade Cândido Mendes, Campos dos Goytacazes, Mestrado em Planejamento Regional e Gestão de Cidades, 2013.

SANT'ANNA, Marina Del-Negro Coque. Elaboração de um modelo de estrutura espacial para o sistema administrativo do novo estado do Rio de Janeiro. Revista Brasileira de Geografia. Rio de Janeiro, v.38, n.3, jul/set. 1976, p. 31-92.

SANTOS, Milton. A natureza do espaço. São Paulo, Edusp, 2001.

SANTOS, Angela Moulin S. Penalva. NAZARETH, Paula Alexandra. Crise fiscal e seus impactos nas relações interfederativas: o caso dos municípios fluminenses. Geo UERJ, Rio de Janeiro, N.31, p.1-33, 2017.

SARMENTO, Carlos Eduardo B. A arquitetura do impossível: a estruturação do Partido Autonomista do Distrito Federal e o debate autonomista nos anos 1930. In: FERREIRA, Marieta de Moraes (coord.) Rio de Janeiro: uma cidade na história. Rio de Janeiro, Editora da Fundação Getúlio Vargas, 2015, p. 39-65.

SILVA, Augusto César Pinheiro da. A produção acadêmica sobre a gestão do território no Estado do Rio de Janeiro: o projeto FAPERJ 2008-2011 no geTERJ da PUC-Rio. GEOPUC - Revista do Departamento de Geografia da PUC-Rio. Ano 4, n. 7, $2^{\circ}$ sem. 2011.

TEIXEIRA, Marlene P. V. Padrões de ligações e sistema urbano: uma naalise aplicada aos estados da Guanabara e Rio de Janeiro. Revista Brasileira de Geografia, Rio de Janeiro, 37 (3), jul/set. 1975, p. 16-55.

URANI, André. Trilhas para o Rio: do reconhecimento da queda à reinvenção do futuro. Rio de Janeiro: Campus/ Elsevier, 2008.

URANI, André. GIAMBIAGI, André. Rio: a hora da virada. Rio de Janeiro: Campus/Elsevier, 2011.

VELLOSO, João Paulo dos Reis. (Org.). A hora e a vez do Rio de Janeiro e o novo governo: desenvolvimento, segurança e favelas. Rio de Janeiro, José Olympio, 2007.

\section{Linovaldo Miranda Lemos}

Professor da Licenciatura em Geografia do Instituto Federal Fluminense, Campus Centro-Campos dos Goytacazes. Atua nas áreas de Geografia Política, Ensino de Geografia e Geografia do estado do Rio de Janeiro. Doutor em Geografia pela UFRJ e atualmente pesquisador de pós-doutorado no Instituto de Geociências da Universidade Estadual de Campinas (Unicamp). E-mail: linovaldomlemos@gmail.com 